\title{
A ilusão de uma sociedade da informação na Ciência da Informação: o termo sob a perspectiva crítica de Mattelart, Bauman e García Canclini
}

\author{
Ciro Athayde Barros Monteiro \\ Doutor; Universidade Estadual Paulista, Marília, SP, Brasil; \\ cirocosmos@gmail.com \\ Oswaldo Francisco de Almeida Junior \\ Doutor; Universidade Estadual Paulista, Marília, SP, Brasil; \\ ofaj@ofaj.com.br
}

\begin{abstract}
Resumo: Este estudo faz reflexão acerca do termo "sociedade da informação", amplamente empregado nos artigos da área de Ciência da Informação, tentando compreender se a expressão é utilizada de forma "passiva" ou "crítica" e quais os impactos que essa noção traz ao campo. Para tanto, o objetivo foi analisar o uso do termo "sociedade da informação" na área em âmbito nacional e internacional. Trata-se de revisão de literatura feita por meio de duas plataformas, sendo a base Library and Information Science Abstracts, que continua sendo referência de serviço internacional de resumo e indexação destinado a profissionais de bibliotecas e outros especialistas em informação, e a Base de Dados de Referência de Artigos de Periódicos em Ciência da Informação, que se tornou referência em pesquisa na área de Ciência da Informação no Brasil. Os resultados demonstraram que mais de $80 \%$ dos pesquisadores, tanto nacionais como internacionais, utilizam o termo de forma passiva em seus textos. Com base nesses dados, o artigo recorre às ideias de Mattelart, Bauman e García Canclini e conclui refletindo acerca dos riscos de a área aceitar a noção de "sociedade da informação" de forma acrítica. Aponta, por meio dos autores, que esse termo foi criado para amenizar as atrocidades promovidas pela ampliação dos interesses econômicos em escala planetária, expandindo a atuação do capital livre que tornou o mundo do trabalho móvel e substituível, além de impor a valorização da produção cultural e científica dos países ricos.
\end{abstract}

Palavras-chave: Sociedade da Informação. Sociedade do Conhecimento. Globalização. Sociedade Global. Ciência da Informação.

\section{Introdução}

A ideia de que o mundo está vivenciando uma "sociedade da informação (SI)" na qual o conhecimento pode ser compartilhado por todos, principalmente por 
aqueles que nasceram em meio às transformações promovidas pelo surgimento e pela popularização da internet, tem sido bastante utilizada pelos pesquisadores da área de informação. Esse termo tem sua origem atribuída à concepção de cientistas estadunidenses, como Machlup (1962), no livro The production and distribution of knowledge in the United States, e Parker (1973), no Information and society, ou a autores japoneses, como Hayashi (1969) na obra The Information Society: from hard to soft, e Masuda (1968), no Introdução à Sociedade da Informação, ganhando destaque nas décadas posteriores.

A partir dos anos 1990, influenciados pelas teorias que surgiram no século XIX sobre o fim da história e da ideologia, as quais posteriormente foram associadas à ideia de informação global, o termo "sociedade da informação" passou a ser amplamente empregado na área atingindo o ápice das discussões no Brasil nos anos 2000. Em 2002, a pesquisadora Lídia Silva de Freitas publicou pesquisa problematizando o uso da expressão "sociedade da informação" na área de informação, baseando-se em três áreas do conhecimento: Ciência da Informação, Biblioteconomia e Arquivologia. Neste período, o uso da expressão crescia significativamente, juntamente a expressões como "sociedade do conhecimento (SC)", "era da Informação (EI)" e "era do conhecimento (EC)" que, na maioria dos casos, eram utilizadas como sinônimos.

Naquele momento, a pesquisadora preocupou-se em averiguar a origem dessas expressões, seus fundamentos e, principalmente, qual noção discursiva de "sociedade da informação" estava sendo empregada nessas áreas de informação. Assim sendo, Freitas (2002) fez revisão de literatura e utilizou a base de dados Library and Information Science Abstracts (LISA) para analisar a literatura da área de informação e a base American Economic Association (ECONLIT), que cobre a produção textual internacional em economia, finanças públicas e indústria, para compreender o envolvimento dos aspectos econômicos nos fundamentos da ideia de "sociedade da informação".

Com levantamento de dados aparentemente próximo ao realizado por Duff (1995), porém com recorte mais extenso, Freitas (2002), por meio da base LISA, analisou a produção do período de 1968 a 1999 e constatou que houve crescimento significativo da utilização da expressão "sociedade da informação" 
na área de informação. Em 1975, apareceu o primeiro uso da expressão, passando para 38 em 1988 e 135 em 1998. Na literatura econômica, por meio da base ECONLIT, a frequência anual de utilização da expressão não foi significativa, já que o primeiro uso aparece em 1983, passando para 4 em 1988 e 8 em 1998. Notou-se que comparada à área de informação, nas ciências econômicas pouco se utilizou a expressão, além de ter começado tardiamente. Neste ponto, a autora faz algumas reflexões para tentar explicar esta primazia da área de informação, apontando para o fato de que o campo, por assumir uma área do conhecimento que é reconhecidamente interdisciplinar, acaba por abraçar muitas áreas, como, por exemplo, econômica, sociológica, antropológica, etc., em que tais ideias não são majoritárias. Pelo fato de a área anunciar essa suposta "sociedade da informação", Freitas (2002) levanta algumas questões: houve transformações importantes nos fundamentos da atual acumulação capitalista quanto às instâncias de geração de valor? Se a "sociedade da informação" é inevitável, ou mesmo fato consumado, por que tantos esforços nacionais e internacionais para implementála?

Com o objetivo de dar continuidade às reflexões empreendidas no início do século XXI por Freitas (2002), analisaremos neste artigo o uso da expressão "SI" na CI entre os anos de 2012 e 2016 em âmbito nacional e internacional. Além disso, baseado nas ideias de Freitas (2002) acerca dos usos da expressão "SI" de forma "crítica" ou "passiva", este último, segundo a autora, desconsidera os fundamentos que deram origem à ideia que serviu de estratégia para os estadunidenses no processo de domínio econômico global.

Assim sendo, entendemos por uso "passivo" da expressão "sociedade da informação" a ideia vinculada à afirmação de que a existência dessa dita sociedade em que todas as pessoas em um contexto mundial, e principalmente os jovens, apropriam-se das informações disseminadas pelos dispositivos tecnológicos e educacionais. O uso "crítico" tende a mostrar a origem do termo, problematizar a ideia, revelar quais interesses a expressão atende, e principalmente, denunciar as desigualdades e o abismo social que existe em relação ao acesso à informação no mundo. Nesse sentido, verificaremos se os termos são utilizados de forma "passiva" ou "crítica". 
Os trabalhos de Duff (1995) e de Freitas (2002) buscaram dar conta de refletir acerca do uso dessas expressões (SI, EI, EC), de que maneira esse uso está vinculado aos interesses do capital e como pode influenciar os destinos e as abordagens da área. Os estudos dos autores analisaram o uso da expressão até 1999, de forma que serviram de base para o desenvolvimento do empreendimento atual, que consiste em analisar a utilização recente da expressão, ou seja, a continuidade do uso passivo do termo nos últimos anos, mesmo após as inúmeras críticas realizadas nos anos 2000.

Feito este levantamento, o artigo abre diálogo com três autores que se destacaram no processo de compreender as novas configurações sociais provenientes da dita globalização: Armand Mattelart, Sigmund Bauman e Néstor García Canclini. Os três refletiram de forma sistemática acerca de como essa ideia de "sociedade da informação" foi criada e disseminada no mundo e de que maneira a CI está sendo negligente ao utilizar essa noção de modo acrítico.

\section{Percurso metodológico}

Trata-se de revisão de literatura cuja intenção foi entender de que maneira a aceitação passiva da ideia de "sociedade da informação" pode impactar no desenvolvimento de pesquisas na CI com grupos que, aparentemente, vivem à margem dessa sociedade, como jovens encarcerados, por exemplo. Para tanto, selecionamos duas bases para analisar tanto a produção nacional como a internacional: Library and Information Science Abstracts (LISA), que continua sendo referência de serviço internacional de resumo e indexação destinado a profissionais de bibliotecas e outros especialistas em informação, e a Base de Dados de Referência de Artigos de Periódicos em Ciência da Informação (BRAPCI), que se tornou referência em pesquisa na área de CI no Brasil.

Devido ao amplo e crescente número de publicações na área, decidiu-se trabalhar com cinco anos da década de 2010 e apenas com o uso da expressão "sociedade da informação", mesmo sabendo que os termos "era da informação" e "sociedade do conhecimento", entre outros, são utilizados, muitas vezes, como sinônimos. Tal delineamento justifica-se pelo fato de não se tratar de uma 
pesquisa bibliométrica, mas de revisão de literatura cujo objetivo é averiguar a afirmação de que a área de CI vem trabalhando há anos com a ideia de que vivemos em uma "sociedade da informação" em que o conhecimento pode ser compartilhado por todos, o que traz consequências ao desenvolvimento de outros objetos de pesquisa na área. Nesse sentido, fez-se buscas nas bases de dados de 2012 a 2016. Foram selecionados apenas artigos publicados em periódicos da área de CI.

\section{Resultados}

Na base de dados LISA, foram encontrados 85 artigos que utilizaram a expressão "sociedade da informação".

Figura 1 - Distribuição dos registros da produção de artigos na base de dados LISA que utilizaram o termo "Sociedade da Informação" na área de CI

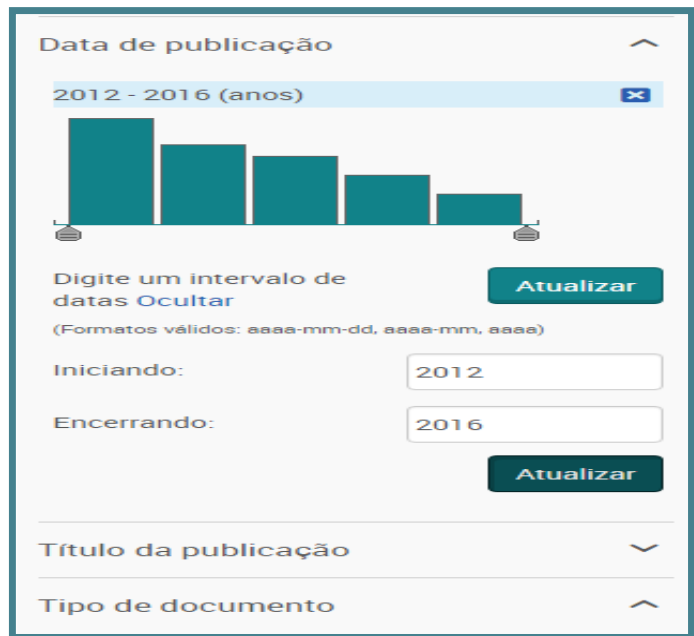

Fonte: Elaborado pelos autores (2020). 
Tabela 1 - Uso da expressão "Sociedade da Informação" de forma crítica e passiva base de dados LISA

\begin{tabular}{c|c|c|c}
\hline Ano & Registros & Crítica & Passiva \\
\hline 2012 & 27 & 06 & 21 \\
\hline 2013 & 20 & 04 & 16 \\
\hline 2014 & 17 & 02 & 15 \\
\hline 2015 & 13 & 02 & 11 \\
\hline 2016 & 08 & 01 & 07 \\
\hline Total & 85 & 15 & 70 \\
\hline & \multicolumn{3}{|c}{ Fonte: Elaborado pelos autores $(2020)}$.
\end{tabular}

Tanto na Figura 1 quanto por meio do Tabela 1, é possível perceber que, durante o período analisado, houve diminuição significativa com relação à utilização da expressão. A problemática aqui não se restringe à quantidade, apesar de os dados demonstrarem que a expressão continua a ser utilizada. O questionamento se refere também à forma como esse termo é utilizado, ou seja, de maneira "crítica" ou "passiva", conforme noção cunhada por Freitas (2002). Assim sendo, além de fazer as buscas, os artigos foram lidos para que fosse possível constatar a forma de uso desses enunciados.

Dos 85 artigos que empregaram a expressão, apenas 15 foram utilizados de forma crítica. Grande parte que usou a expressão de forma crítica, o fez por meio de um percurso histórico/epistemológico da expressão, ou apresentou grupos sociais que são excluídos dessa suposta sociedade. Já os manuscritos que aceitam a expressão de forma passiva, muitas vezes utilizam frases como, por exemplo, "Na atual sociedade da informação", "Estamos na sociedade da informação" e/ou "A nova sociedade da informação".

A Figura 2 demonstra a porcentagem de uso crítico e passivo da expressão "sociedade da informação" na base LISA. 
Figura 2 - Distribuição dos registros da produção de artigos que utilizaram o termo "Sociedade da Informação" de forma "passiva" ou "crítica" na área de CI indexada na base de dados LISA

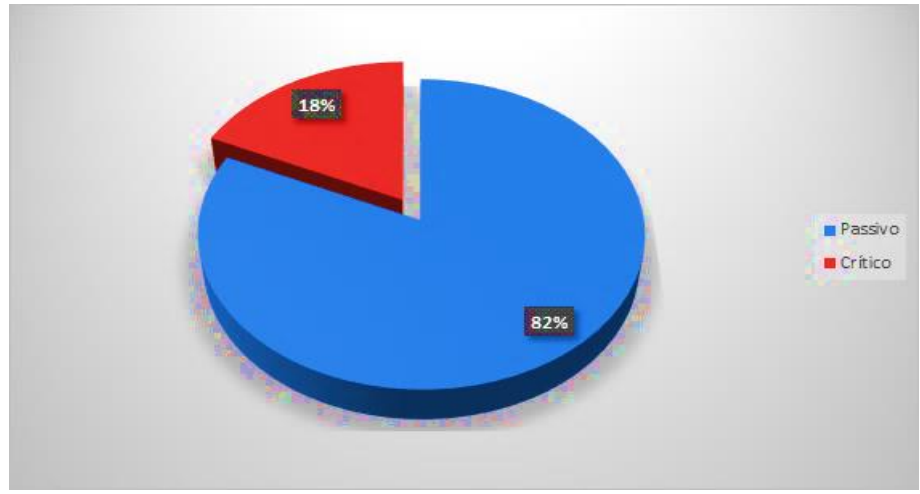

Fonte: Elaborado pelos autores (2020).

Com relação à produção nacional, encontramos muitas semelhanças com o levantamento feito sobre os periódicos da base internacional. Na BRAPCI, foram encontrados 78 artigos que utilizaram a expressão "sociedade da informação". Desses, a maior porcentagem foi usada de forma passiva, como é possível observar na Figura 3 e apenas 13 foram utilizados de forma crítica, conforme demonstra a Tabela 2 .

Tabela 2 - Uso da expressão "Sociedade da Informação" na base de dados BRAPCI de forma "crítica" ou "passiva"

\begin{tabular}{c|c|c|c}
\hline Ano & Registros & Crítica & Passiva \\
\hline 2012 & 07 & 01 & 06 \\
\hline 2013 & 22 & 04 & 18 \\
\hline 2014 & 22 & 05 & 17 \\
\hline 2015 & 14 & 03 & 11 \\
\hline 2016 & 13 & 00 & 13 \\
\hline Total & 78 & 13 & 65 \\
\hline
\end{tabular}

Fonte: Elaborado pelos autores (2020) 
Figura 3 - Distribuição dos registros da produção de artigos que utilizaram o termo "Sociedade da Informação" na área de CI na base de dados BRAPCI

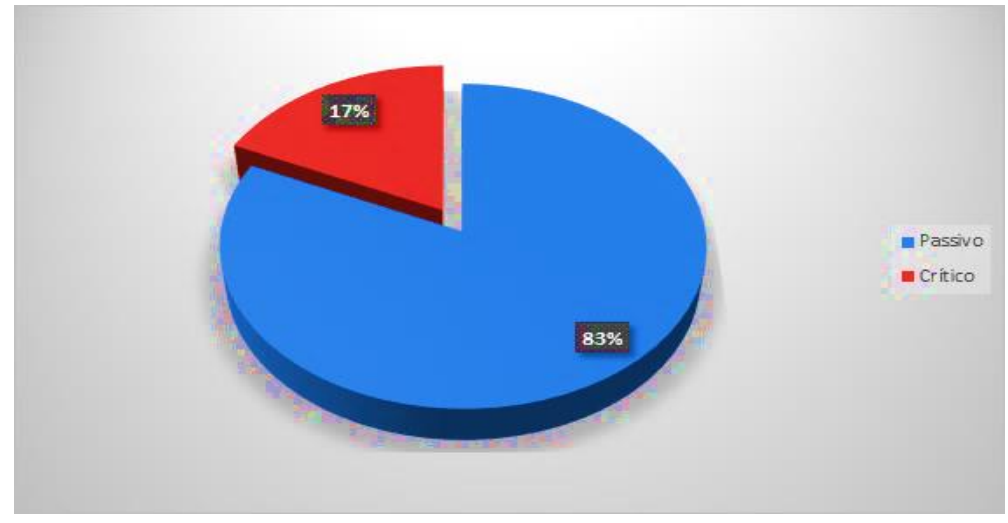

Fonte: Elaborado pelos autores (2020).

Assim como a produção internacional, grande parte dos artigos nacionais que utilizou a expressão de forma crítica o fez por meio de um percurso vinculado às questões relacionadas à memória, ao interculturalismo e aos aspectos históricos e epistemológico da expressão. Ou, de alguma maneira, refletiu acerca da exclusão digital e das desigualdades sociais. Outro aspecto semelhante à produção internacional, esteve relacionado à forma como os artigos que aceitam a expressão de forma passiva utilizaram frases para abordar essa suposta sociedade. Há expressões como "Tempo de sociedade da informação", "Privacidade na sociedade da informação", "A nova sociedade da informação", "Internet na sociedade da informação", "Desenvolvimento na sociedade da informação".

De forma geral, foi possível perceber que a expressão continua a ser utilizada tanto na produção nacional quanto internacional e há supremacia do uso passivo do termo feito pela área. Nesse sentido, parece aceitável a afirmação feita no início deste artigo sobre a ideia de uma "sociedade da informação", ou seja, de que a plenitude de acesso à informação tem sido um imperativo aceito pela área há mais de duas décadas. Ainda, enaltece a crítica de que a aceitação passiva dessa ideia pode corroborar para ausência de uma orientação política ou de fomento à pesquisa no caminho da percepção e ação a favor dos excluídos sociais.

Ao ler autores como Zygmunt Bauman, Néstor Canclini e Armand Mattelart é possível perceber que o vocabulário "sociedade da informação" apareceu como logotipo da ideia de globalização e que ambos contêm a mesma ambiguidade (MATTELART, 2006). Além disso, que para compreender como 
essas narrativas estão vinculadas ao processo de fragmentação e desrespeito às diversidades culturais, é necessário refletir acerca da ideia de globalização. Dessa forma, este artigo não teve como pressuposto fazer um percurso histórico sobre o surgimento da ideia de "sociedade da informação" (DUARTE, 2003; DUFF, 1995; FREITAS, 2002; HAYASHI, 1969; MASUDA, 1968; NUNES; ALMEIDA JUNIOR, 2013; PARKER, 1973), tampouco tentar abordar ou refletir acerca da literatura existente sobre o assunto, tendo em vista que é vasta e que qualquer tentativa de exaustão estaria condenada à incompletude (NUNES; ALMEIDA JUNIOR, 2013).

No entanto, por meio principalmente dos três autores, que fazem críticas a essas narrativas, buscamos refletir como as transformações ocorridas nas últimas décadas, que foram responsáveis por forjar uma ideia de "sociedade da informação", impactaram no esfacelamento das sociedades e culturas, contribuindo ainda mais para o abismo entre os povos.

Importante salientar que este primeiro questionamento empreendido aqui acerca do uso passivo e crítico do termo "sociedade da informação" na CI faz parte da necessidade de prestar serviço à humanidade, questionando as premissas dos modos de vida que causam sofrimento humano, como revela Bauman (2001):

\footnotetext{
Não formular certas questões é extremamente perigoso, mais do que deixar de responder às questões que já figuram na agenda oficial; ao passo que responder o tipo errado de questões com frequência ajuda a desviar os olhos das questões realmente importantes. O preço do silêncio é pago na dura moeda corrente do sofrimento humano. Fazer as perguntas certas constitui, afinal, toda a diferença entre sina e destino, entre andar à deriva e viajar. Questionar as premissas supostamente inquestionáveis do nosso modo de vida é provavelmente o serviço mais urgente que devemos prestar aos nossos companheiros humanos e a nós mesmos. (BAUMAN, 2001, p. 11).
}

Nessa perspectiva, Mattelart, Bauman e García Canclini fazem críticas sistemáticas às ideias de "sociedades globais" e "globalização" que, supostamente, teriam o objetivo de integração de povos e culturas. Dentro desses discursos, estão as narrativas de "sociedade do conhecimento e da informação". Esses três autores foram escolhidos pela afinidade e profundidade discursiva com que denunciam as perversidades promovidas pela expansão do capital em escala 
planetária, principalmente no que se refere ao respeito às culturas, às diversidades e às relações de trabalho, revelando o discurso "globalizante" como forma de amenizar as atrocidades resultantes do funcionamento do capital. É por esse caminho que seguiremos dialogando com os autores.

\section{Mattelart: a utopia globalizada da "sociedade da informação"}

O sociólogo belga Armand Mattelart, pensador de inspiração crítica e marxista, autor de inúmeras obras sobre cultura de massa e indústria cultural, foi quem primeiro alertou para a necessidade de se refletir acerca da ideia de "globalização", objetivando a compreensão de como se deu o processo de criação e aceitação, por grande parte dos pesquisadores, da expressão "sociedade da informação". Professor catedrático de ciências da informação e comunicação da Universidade de Paris VIII, desenvolveu estudos sistemáticos sobre informação e comunicação, além de se debruçar epistemologicamente sobre expressões utilizadas pela ciência, principalmente pelas áreas de informação e comunicação.

Um desses estudos foi a obra História da Sociedade da Informação, na qual o autor analisa de que forma a noção de "sociedade da informação" foi introduzida nas narrativas, que se deu por meio da gestação de promessas de uma reorganização do mundo, que foi e continua a ser amplamente utilizada pelos governos e discursos científicos sem qualquer reflexão acerca de suas origens.

Em A globalização da comunicação, o autor analisa de que maneira a nova elite mundial tem assumido papel messiânico como sendo os novos agentes da paz mundial. Com o discurso de "planetarização da democracia" e "integração dos povos" (MATTELART, 2006, p. 123) essa elite utiliza-se da expressão "globalização" como eufemismo para mascarar os interesses do livre mercado global.

Ambos os livros são essenciais para a compreensão de como o vocabulário da "sociedade da informação" se impôs como um logotipo da assim chamada globalização, tendo em vista que essas noções partilham da mesma ambiguidade e "[...] coloca uns contra os outros projetos contrastados de integração mundial que remetem a valores estéticos, éticos e políticos antagônicos" (MATTELART, 
2006, p. 171). Vale ressaltar que este texto reitera e tenta deixar latente o exacerbado uso passivo da expressão "sociedade da informação" e da necessidade de estabelecer críticas ao termo.

Embora se possa observar com facilidade o emprego demasiado do termo sociedade da informação e de seus vários cognatos, percebe-se também certa fragilidade em sua formulação. Pouco se problematiza a expressão, utilizando-a, muitas vezes, como algo estabelecido. (NUNES; ALMEIDA JÚNIOR, 2013, p. 31).

O uso da expressão como algo estabelecido é extremamente perverso, pois esconde o que de fato vem acontecendo no mundo, ou seja, o estabelecimento de uma nova ordem mundial global na qual o modelo de administração de empresas toma conta das relações sociais em nível mundial para maximizar os lucros.

A globalização é, primeiramente, um modelo de administração de empresas que, respondendo à crescente complexidade do ambiente da concorrência, procede da criação e da exploração de competências em nível mundial, objetivando maximizar os lucros e consolidar suas fatias de mercado. (MATTELART; MATTELART, 2000, p. 125).

No entanto, a expressão "globalização", assim como "sociedade da informação", vem sendo utilizadas pelas áreas e, em grande medida pela CI, como se a área fosse conivente com as narrativas de que o mundo está diante de um processo global de unificação, integração e respeito às pessoas, às culturas e às identidades. Um mundo no qual todos têm acesso à informação, aos dispositivos e as tecnologias. Essa ideia de universalização do acesso à informação e ao conhecimento, que seja compartilhado por todos, sempre foi um pressuposto questionado por Armand Mattelart.

O autor relata que as "forças vivas da sociedade civil" (MATTELART, 2006, p. 9) procuraram escapar da lógica de desenvolvimento desigual e do imperativo da Global War em detrimento das tecnologias de informação e comunicação como responsáveis por acabar as desigualdades de acesso à informação. De acordo com Mattelart (2006), a partir dessa lógica e com a emergência do paradigma tecnoinformacional impulsionado pelas máquinas inteligentes durante a Segunda Guerra Mundial, surgiu a necessidade de forjar o 
conceito de "sociedade da informação", expandindo as limitações da ideia de informação.

\begin{abstract}
A imprecisão que envolve a noção de informação coroará a de "sociedade da informação". A vontade precoce de legitimar politicamente a ideia da realidade hic et nunc desta última justificará os escrúpulos da vigilância epistemológica. A tendência a assimilar a informação a um termo proveniente da estatística (data/dados) e a ver informação somente onde há dispositivos técnicos se acentuará. Assim, instalar-se-á um conceito puramente instrumental de sociedade da informação. Com a atopia social do conceito apagar-seão as implicações sociopolíticas de uma expressão que supostamente designa o novo destino do mundo. (MATTELART, 2006, p. 71).
\end{abstract}

Esse conceito forjado, que apagou as implicações sociopolíticas dos novos rumos das relações planetárias e tomou o mundo, foi abraçado pela ciência e amplamente disseminado. Nessa perspectiva, é possível perceber por meio das ideias de Mattelart que a elite econômica mundial teve de criar o conceito de "sociedade da informação" para amenizar as atrocidades promovidas pela ampliação dos seus interesses econômicos em escala planetária.

Essa expressão apenas coroou uma noção que já vinha sendo trabalhada desde a década de 1980 com o conceito de "globalização". Para Mattelart, o conceito de "globalização" surgiu para delimitar a fase de integração mundial em relação às novas lógicas transfronteiriças dos diferentes fundamentos institucionais do sistema de comunicação dos Estados Nacionais. Teve como objetivo "[...] estabelecer as novas regras do processo de desregulamentação que exigiu profunda alteração do modelo econômico e social" (MATTELART; MATTELART, 2000, p. 123).

Para Mattelart e Mattelart (2000), o discurso da "globalização" carrega palavras significativas, como "integração", que se refere à lógica empresarial da organização funcional das grandes unidades econômicas; e o termo "global" -em inglês, é sinônimo de holistic -, que "[...] remete explicitamente a uma filosofia holística, ou seja, à ideia de unidade totalizante ou unidade sistemática" (MATTELART; MATTELART, 2000, p. 125). Nesta perspectiva, o que nos parece evidente é que a expressão "globalização" é mais uma das várias expressões, com noções instrumentais, criadas para atender às lógicas mercantis 
à revelia dos cidadãos. Como destacam os autores, esta “[...] linguagem funcional constitui um prêt-à-porter ideológico que mascara os desvios da nova ordem mundial" (MATTELART; MATTELART, 2000, p. 149). Com o objetivo de impedir o posicionamento crítico, a noção de "globalização" abraçou as transformações tecnoeletrônicas da sociedade contemporânea e substituiu a "diplomacia dos canhões" pela "diplomacia das redes", redefinindo as relações que os Estados Unidos mantêm com o resto do mundo. Essas redefinições destacaram os Estados Unidos como a primeira "sociedade global" da história.

\footnotetext{
Os Estados Unidos se tornaram a primeira sociedade global da história. Eles prefiguram a "sociedade global" em escala mundial. Como a revolução tecnociêntífica made in USA cativa a imaginação de toda a humanidade (a conquista espacial demonstra isso amplamente), é inevitável que ela conduza as nações menos avançadas a alinhar-se a esse polo inovador e que as incite a imitá-la tomando emprestados os seus métodos, as suas técnicas e práticas de organização. (MATTELART, 2006, p. 99).
}

Dessa forma, os estadunidenses perceberam a efetividade de se trabalhar com "diplomacia de redes" ao invés de canhões (sem entrar nas discussões acerca da manutenção da indústria bélica e das guerras fora de seu território), passando a vender cultura enlatada para todo o mundo, incitando pessoas dos mais variados lugares do planeta a imitá-los e aceitá-los, tanto em seu modo de vida e cultura, como reproduzindo conceitos no âmbito da ciência sem qualquer reflexão.

Nesse sentido, existe a necessidade amiúde de retomar as reflexões feitas por Armand Mattelart sobre as configurações do mundo atual. O professor Carlos Araújo, há quase 10 anos, criticou o pouco uso das ideias do autor no Brasil pela CI, argumentando que ele era amplamente utilizado pelas áreas de informação, porém no campo brasileiro teve adesão tímida. Segundo Araújo, o motivo era a configuração da área de informação social que estava “[...] voltada para as questões técnicas e tecnológicas da informação, a contribuição de ideias oriundas de um pensamento crítico como o de Mattelart acaba se tornando muito reduzida" (ARAÚJO, 2009, p. 117).

Nesta perspectiva, após uma década, esse cenário supostamente não tem sofrido grandes transformações. No entanto, diante desse quadro, resgatar autores 
como Mattelart não só é essencial à área como permite afastar e questionar como o campo vem trabalhando com essas "ilusórias soluções globais" (MATTELART; MATTELART, 2000, p. 186) que negam ao cidadão o direito de pensar outros caminhos de integração supranacional.

\section{Bauman: consequências humanas de uma globalização líquida}

O pensador polonês Zygmunt Bauman, talvez, seja um dos autores contemporâneos que mais refletiu acerca das transformações ocorridas na sociedade moderna, principalmente sobre a ideia de globalização e das novas tecnologias, retratando o impacto que ideologias e dispositivos promoveram na reconfiguração dos espaços, do tempo e das identidades. Em seu clássico Globalização: as consequências humanas, escrito em 1998 e que continua leitura essencial no processo de tentar compreender as transformações da sociedade atual, aborda a "globalização" sob várias perspectivas, tanto pelo viés de classe e Estado-nação, como pelo olhar sobre o sistema prisional. Interessante notar que o pensador finaliza o livro refletindo acerca do aumento do distanciamento promovido entre povos e Estados, promovido pela ideia de globalização, que transformou as leis e favoreceu o isolamento e o crescimento do sistema prisional.

Em Modernidade Líquida, o autor trata da fluidez das relações sociais no mundo contemporâneo a qual transformou as relações que estavam estabelecidas no que chama de "modernidade sólida" (BAUMAN, 2001, p. 148) essa fluidez trouxe transformações significativas nas identidades, na estrutura das cidades e, principalmente, no modo de vida diária das pessoas. É possível perceber que ambos os termos, tanto "globalização" como "modernidade líquida", são importantes para trazer luz aos questionamentos feitos neste artigo, ou seja, a uma dita "sociedade da informação" que seria responsável por integrar povos, cultura e mergulhar todos os jovens em uma sociedade global.

Dessa forma, principalmente esses dois livros serviram de base para a confecção deste tópico. Iniciamos esta narrativa destacando o que Bauman sobre o que ele chama de "capital leve" (BAUMAN, 1999, p. 56) demonstrando que a principal característica da sociedade atual é o fato de que o capital conseguiu 
romper com as amarras que o prendiam aos locais e que forçava o enfrentamento direto com os trabalhadores, tornando-se livre para atuar em qualquer localidade do mundo. Provavelmente essa seja uma das principais contribuições do autor no processo de compreensão das transformações da sociedade moderna.

Ao tratar das mudanças ocorridas no capital software, o escritor argumenta que a metáfora do panóptico foi uma das facetas fundamentais da imaginação sociológica acerca da modernização do poder e do controle. No entanto, a sociedade contemporânea ampliou suas estratégias de controle, tornando os desafios atuais diferentes, ao passo que o modelo panóptico tradicional, se perseguido com rigor excessivo, torna suas análises acerca da sociedade atual "irrelevantes ou inteiramente contraproducentes" (BAUMAN, 1999, p. 57). Para ilustrar essas novas necessidades e estratégias de pensar um modelo panóptico atualizado, Bauman (1999) cita o "superpanóptico" criado pelo historiador estadunidense Mark Poster.

\begin{abstract}
No seu brilhante ensaio sobre os bancos de dados eletrônicos como uma versão ciberespacial atualizada do Panóptico, Mark Poster diz que nossos corpos são fisgados dentro das redes, dos bancos de dados, nas auto-estradas da informação - e assim todos esses locais de armazenamento de informação onde nossos corpos são, por assim dizer, amarrados informaticamente não mais oferecem refúgio à observação ou uma barreira em torno da qual se possa traçar uma linha de resistência. A armazenagem de quantidades maciças de dados, ampliadas a cada uso de um cartão de crédito e virtualmente a cada ato de compra, resulta, segundo Poster, num superpanóptico mas com uma diferença: os vigiados, fornecendo os dados a armazenar, são fatores primordiais — e voluntários — da vigilância. (BAUMAN, 1999, p. 58).
\end{abstract}

É notório que a sociedade atual está passando por novas formas de controle e que um "superpanóptico" tem ganhado, cada vez mais, força para "fisgar corpos" em redes retroalimentadas de informações pessoais pelos próprios usuários. Bauman cita o telefone celular como símbolo dessa sociedade caracterizada por ele como "pós-panóptica" e que tornou o poder extraterritorial, dando "[...] aos detentores do poder uma oportunidade verdadeiramente sem precedentes: eles podem se livrar dos aspectos irritantes e atrasados da técnica de poder do Panóptico" (BAUMAN, 2001, p. 20). Interessante pensar que as anulações de tempo e espaço promovidas pelas novas tecnologias, em uma 
sociedade pós-panóptica, não cumprem o papel anunciado pelo discurso da "sociedade da informação" de homogeneização da condição humana. Ao invés disso, ela fragmenta e polariza identidades, pois, ao mesmo tempo que emancipa algumas pessoas de restrições territoriais tornando extraterritoriais os significados geradores de comunidade, "[...] desnuda o território, no qual outras pessoas continuam sendo confinadas, do seu significado e da sua capacidade de doar identidade" (BAUMAN, 1999, p. 25).

Além da questão dos paradoxos das novas tecnologias que tanto aproximam quanto distanciam e dividem identidades, Bauman aponta o problema do isolamento das megalópoles e da formação de fortalezas individuais, que corroboram com o distanciamento e a segregação entre pessoas, grupos e culturas.

\begin{abstract}
Os medos contemporâneos, os medos urbanos típicos, ao contrário daqueles que outrora levaram à construção de cidades, concentramse no inimigo interior. Esse tipo de medo provoca menos preocupação com a integridade e a fortaleza da cidade como um todo - como propriedade coletiva e garante coletivo da segurança individual — do que com o isolamento e a fortificação do próprio lar dentro da cidade. Os muros construídos outrora em volta da cidade cruzam agora a própria cidade em inúmeras direções. Bairros vigiados, espaços públicos com proteção cerrada e admissão controlada, guardas bem armados no portão dos condomínios e portas operadas eletronicamente - tudo isso para afastar concidadãos indesejados, salteadores de estrada, saqueadores ou outros perigos desconhecidos emboscados extramuros. Em vez da união, o evitamento e a separação tornaram-se as principais estratégias de sobrevivência nas megalópoles contemporâneas. Não há mais a questão de amar ou odiar o seu vizinho. (BAUMAN, 1999, p. 56).
\end{abstract}

Essa nova conjuntura global que segrega e impede o contato com os vizinhos tem sido a lógica da configuração da sociedade contemporânea. Exemplo disso são os grandes conglomerados de condomínios em que, na maioria das vezes, não se conhece o vizinho que faz barulho na parede ao lado. Assim sendo, essa crescente ausência de contato entre pessoas e os inúmeros "medos líquidos" (BAUMAN, 2008, p. 111) que atormentam todas as classes sociais foram provocados, segundo Bauman (2008) por uma "globalização negativa" que se caracterizou por ser uma globalização “[...] altamente seletiva do comércio e do capital, da vigilância e da informação, da coerção e das armas, do crime e do 
terrorismo que desdenham de soberanias nacionais e desrespeitam as fronteiras" (BAUMAN, 2008, p. 126).

Essa "globalização negativa" (BAUMAN, 2008, p. 125) também é responsável por fomentar uma "ideia de segurança" estabelecida nos governos que pretendem passar a imagem de cidade segura, com o objetivo de receber "votos" e mostrar que estão fazendo algo pelos governados. Tais medidas, como a construção de novas prisões e o aumento das penas, impactam positivamente na popularidade do governo.

A construção de novas prisões, a redação de novos estatutos que multiplicam as infrações puníveis com prisão e o aumento das penas - todas essas medidas aumentam a popularidade dos governos, dando-lhes a imagem de severos, capazes, decididos e, acima de tudo, a de que "fazem algo" não apenas explicitamente pela segurança individual dos governados mas, por extensão, também pela garantia e certeza deles — e fazê-lo de uma forma altamente dramática, palpável, visível e tão convincente. (BAUMAN, 1999, p. 127).

Além do interesse dos governos em aumentar a popularidade e se perpetuar no poder, existe a necessidade de agradar os "olhares externos", ou seja, é preciso manter uma imagem de "ambiente seguro" para que as forças globais do mercado possam criar confiança e fazer com que o investidor tenha tranquilidade em investir no país. Nessa perspectiva, Bauman relata que os governos se esforçam para manter a imagem das cidades limpas, com qualidade de policiamento e sem ladrões e mendigos nas ruas.

No mundo das finanças globais, os governos detêm pouco mais que o papel de distritos policiais superdimensionados; a quantidade e qualidade dos policiais em serviço, varrendo os mendigos, perturbadores e ladrões das ruas, e a firmeza dos muros das prisões assomam entre os principais fatores de "confiança dos investidores" e, portanto, entre os dados principais considerados quando são tomadas decisões de investir ou de retirar um investimento. (BAUMAN, 1999, p. 128).

No mundo do "capital leve", não existem barreiras ou limites de atuação do capital. Os detentores do capital são livres para procurar a maior porcentagem de lucro e segurança nos investimentos, o que potencializa as possibilidades de exploração de trabalho mal remunerado e precarizado. Esse "capital leve", sem 
paredes e localização, tornou o mundo do trabalho "móvel" e facilmente “substituível”. Para ilustrar essa lógica, Bauman dá o exemplo dos mecânicos de automóveis que não são treinados para consertar motores quebrados ou danificados, mas apenas para retirar as peças e as substituírem. Eles não têm a ideia da estrutura interna da peça e de como funcionam.

O autor observa: "Por que gastar tempo com consertos que consomem trabalho, se não é preciso mais que alguns momentos para jogar fora a peça danificada e colocar outra em seu lugar?” (BAUMAN, 2001, p. 186). Nesse mundo onde tudo é substituível, a "globalização" se utiliza de "forças anônimas" operando na "terra de ninguém", impondo às economias "nacionais" a condição de efêmeras e extraterritoriais, vinculadas aos interesses dos mercados financeiros globais. "A globalização nada mais é que a extensão totalitária de sua lógica a todos os aspectos da vida" (BAUMAN, 1999, p. 73). Dessa forma, os governos nacionais, em meio a essa desterritorialização dos mercados mundiais e de suas soberanias anuladas, ficam apenas com as atribuições básicas de, por meio do poder, garantir segurança para que as multi-empresas globais possam investir sem riscos.

Além da tarefa de fazer a segurança para empresas, os governos nacionais, por meio de seus legisladores, acabam por preservar determinado tipo de ordem, ou seja, a que favorece a elite política do país e tende a punir, com seus códigos criminais, pessoas que estão fora dessa ordem. Dessa forma, a ordem vigente acaba sendo da exaltação dos mercados globais, na qual roubar os recursos de nações inteiras é chamado de "promoção do livre comércio"; roubar famílias e comunidades inteiras de seu meio de subsistência é chamado "enxugamento" ou simplesmente "racionalização" (BAUMAN, 1999, p. 131). Essa constatação é grave, pois há pouca vontade e pressão política sobre os "legisladores e guardiões" da ordem, no sentido de tornar efetivo o combate ao crime de colarinho branco. A ausência de clamor público pela punição dos crimes de colarinho branco não pode ser comparado ao clamor público feito contra os 
condescendentes por não os colocarem no lugar onde deveriam estar, a prisão. (BAUMAN, 1999, p. 133).

Dessa maneira, essa "globalização" vinculada aos interesses do mercado global, além de não favorecer a punição dos corruptos de colarinho branco, visto que estes estão comprometidos em beneficiar os investidores externos, ainda não colabora com algo que seria um dos preceitos básicos e fundamentais na consolidação de um mundo supostamente globalizado, ou seja, o direito de migração - a possibilidade simples e racional de permitir que famintos possam ir para onde a comida é abundante -, que é negado na maioria das fronteiras.

Todo este cenário, de xenofobia, desterritorialização, desrespeito às localidades e total apoio aos investidores, favoreceu o surgimento do que Bauman chamou de "lugares de consumo coletivo" ou "templos de consumo" (BAUMAN, 2001, p. 114). Lugares nos quais o "[...] consumidor não vai para conversar ou socializar, fica isolado e livre para consumir sem ser interrompido" (BAUMAN, 2001, p. 115).

Nessa perspectiva, para Bauman (2001), o discurso globalizante está a serviço dos grandes capitalistas do mundo e as ideias de união entre povos e culturas são formas de eufemismos para amenizar a tragédia gerada pela liberação do capital global. O autor aponta inúmeras consequências geradas pelo "capital leve”, como dificuldade de reunir pessoas para ações coletivas: “[...] está cada vez mais difícil, talvez até mesmo impossível, reunir questões sociais numa efetiva ação coletiva" (BAUMAN, 1999, p. 76).

Tal ausência de manifestação coletiva, segundo o autor, é resultado do processo crescente e exacerbado de individualização, gerando a ilusão da autocontenção e da autossuficiência do indivíduo

[...] se ficam doentes, supõe-se que foi porque não foram suficientemente decididos e industriosos para seguir seus tratamentos; se ficam desempregados, foi porque não aprenderam a passar por uma entrevista. (BAUMAN, 2001, p. 35).

Além do processo de individualização e da ausência de ações coletivas, a vida passou a ser uma reprodução da sociedade de consumo. Para Bauman (2001), 
todos os membros de uma sociedade de consumo estão correndo por meio da atividade de comprar. Tanto nos supermercados quanto nos templos de consumo, o ato de consumir passa a ser a busca constante e sem fim por modelos de vida em que a felicidade depende das competências e dos esforços individuais.

Dessa maneira, o consumo como extensão e modelo de vida impacta de forma abrupta na vida das pessoas, gerando doenças, ansiedades e a eterna sensação de insatisfação em uma sociedade mergulhada no "rivotril" que satisfaz os interesses da indústria farmacêutica. Até mesmo os relacionamentos e laços afetivos, nessa sociedade fluida e insatisfeita, acabam por supor uma transitoriedade, operando no movimento do casamento para o "viver junto" (BAUMAN, 2001, p. 173).

Essa mobilidade e flexibilidade que caracterizam o "ir às compras" acabam por ser instrumentos ambivalentes de redistribuição das liberdades gerando reações contraditórias, conflitos, fragmentação e ausência de solidariedade. Para Bauman, como essa tarefa tem de ser compartilhada por todos e sob condições diferentes, "[...] divide as situações humanas e induz à competição mais ríspida, em vez de unificar uma condição humana inclinada a gerar cooperação e solidariedade" (BAUMAN, 1999, p. 107).

Foi neste quadro de ausência de solidariedade, individualismo e consumismo como modelo de vida a ser seguido por todos que Bauman (2001) relatou o que significa ser moderno na sociedade software.

\begin{abstract}
Ser moderno passou a significar, como significa hoje em dia, ser incapaz de parar e ainda menos capaz de ficar parado. Movemo-nos e continuaremos a nos mover não tanto pelo adiamento da satisfação como sugeriu Max Weber, mas por causa da impossibilidade de atingir a satisfação: o horizonte da satisfação, a linha de chegada do esforço e o momento da auto-congratulação tranquila movem-se rápido demais. A consumação está sempre no futuro, e os objetivos perdem sua atração e potencial de satisfação no momento de sua realização, se não antes. Ser moderno significa estar sempre à frente de si mesmo, num Estado de constante transgressão. (BAUMAN, 2001, p. 38).
\end{abstract}

Nesse sentido, o mundo moderno e sua tão aclamada e ambivalente ideia de globalização, ao mesmo tempo que aproxima pessoas por meio de suas tecnologias, foi e está sendo responsável por moldar um mundo em que as pessoas 
são incapazes de atingir a satisfação, tornam-se doentes e mergulham no abismo do individualismo, da ausência de solidariedade e da negação do diferente. Guardadas as devidas exceções, a tal "flexibilização" fez das ofertas de emprego algo descompromissado, sem segurança, sem direitos ou aviso prévio. Empregos em que "Ninguém pode, portanto, sentir-se insubstituível - nem os já demitidos nem os que ambicionam o emprego de demitir os outros. Mesmo a posição mais privilegiada pode acabar sendo apenas temporária” (BAUMAN, 2001, p. 185).

Outra questão que merece destaque no processo de "globalização" da economia é no tocante à dependência que os países ditos subdesenvolvidos desenvolvem em relação aos países que controlam os recursos do mundo. Como os governos dos países dependentes não conseguem controlar as contas com recursos próprios, são obrigados a "[...] não só se renderem ao inevitável, mas colaborarem ativamente e de bom grado com os globais" (BAUMAN, 2001, p. 222).

Dessa forma, a caracterização trágica, feita por Bauman (2001) acerca da sociedade global, serve de base para compreensão do surgimento de uma suposta "sociedade da informação" alinhada com os pressupostos básicos de funcionamento de uma globalização líquida, desterritorializada e que tem por interesse potencializar seus lucros pelo mundo.

\section{García Canclini: a interculturalidade necessária em uma globalização imaginada}

Néstor García Canclini, antropólogo argentino que estuda cultura e a pósmodernidade a partir do ponto de vista latino-americano, é um dos grandes autores que não poupa críticas à dita "sociedade da informação e do conhecimento".

Por trabalhar com conceitos de diferença, desigualdade e conexãodesconexão, encontramos no autor reflexões que, de maneira ampla, acabam por abraçar as problemáticas deste artigo, refletindo acerca das diferenças, desigualdades e desconexões das pessoas, servindo à manutenção da ordem social. 
Diante da vasta produção do autor, dois livros foram essenciais para estruturação deste artigo. Em A globalização imaginada, o pensador analisa como a ideia de globalização impactou e continua a promover transformações significativas no processo de produção e circulação de bens culturais, gerando hegemonias, prejudicando os intercâmbios culturais e aumentando as desigualdades sociais.

Em Diferentes, desiguais e desconectados: mapas da interculturalidade, o autor analisa, por meio do interculturalismo, como as identidades, para que possam se afirmar, devido ao processo de unificação capitalista do mundo nas últimas décadas, têm passado por encontros e confrontos, assimilações e repulsas, em uma luta constante de negociações.

Com base nesses pressupostos, tentamos estabelecer reflexões acerca das críticas feitas pelo autor sobre "sociedade da informação e do conhecimento" e "globalização" e a necessidade de compreender cultura e interculturalidade como forma de respeitar as individualidades de pessoas e grupos "desconectados", que são produtos das transformações ocorridas nas últimas décadas da sociedade contemporânea.

Nesse sentido, para García Canclini, quem acredita em uma suposta "sociedade da informação" aceita a ideia utópica de que:

[...] o desenvolvimento social e cultural depende do fato de todos os países integrarem-se na revolução digital e informacional, todos os setores de cada sociedade terem o acesso a "trabalhos inteligentes" mediante as novas capacidades e da conexão com as redes nas quais se obtém informação estratégica. As outras dimensões do desenvolvimento virão por acréscimo. A tecnologização produtiva, a expansão dos mercados e sua integração transnacional incrementarão os ganhos econômicos. Como consequência, o acesso direto e simultâneo à informação vai democratizar a educação e melhorar o bem-estar da maioria. No plano político, crescerão as oportunidades de participação e se descentralizarão as decisões. (GARCÍA CANCLINI, 2009, p. 234).

Essa ideia totalizante de tecnologização está incorporada à maioria dos discursos que tentam apontar os benefícios das transformações ocorridas nas últimas décadas, principalmente no âmbito tecnológico. Notou-se que todas as análises feitas até aqui acerca do discurso utópico sobre "sociedade da 
informação" estavam carregados de palavras como "integração transnacional ou mundial", "revolução digital ou informacional", "democratização do acesso à informação" (GARCÍA CANCLINI, 2009, p. 33), sempre narrando a possibilidade de proporcionar bem-estar a todas as pessoas.

Essas narrativas estão presentes tanto no discurso científico como nos grandes conglomerados de comunicação dos mais variados países do mundo. No entanto, esse discurso é pernicioso, pois o mundo está vivendo degradações da vida social que passam ao largo de serem resolvidos por uma concepção informacional de sociedade.

Tal tragédia pode ser analisada de várias maneiras, tanto pela ausência de condições igualitárias de acesso à informação essenciais para a formação do ser, como pela necessidade de individualizar o atendimento ao educando respeitando suas particularidades, sua cultura e suas demandas.

Nessa perspectiva, García Canclini pondera que educandos, no processo de ensino-aprendizagem, que são tratados como "iguais", ou seja, não têm suas particularidades culturais e demandas individuais respeitadas, também não possuem idênticas possibilidades de aprender.

\begin{abstract}
Uma educação homogênea baseada numa informação universal e estandardizada não gera maior equidade nem democratização participativa. Se prestarmos atenção às múltiplas formas de pertencimento e coesão social, escutaremos uma pluralidade de demandas. São necessárias "adaptações programáticas ao grupo específico" (por exemplo, o bilinguismo em zonas multinacionais), "buscar a pertinência curricular em função das realidades territoriais em que a escola se desenvolve e destinar recursos especiais às zonas de maior vulnerabilidade social e precariedade econômica. (GARCÍA CANCLINI, 2009, p. 235).
\end{abstract}

Nesse sentido, criar programas de inclusão informacional que não levem em conta as peculiaridades culturais e as demandas individuais são tentativas fadadas ao fracasso. Esses são alguns dos problemas da ausência de postura crítica acerca do discurso de integração e homogeneização dos povos por meio de tecnologias. Sobre essas generalizações conceituais, o termo "sociedade do conhecimento", que muitas vezes é utilizado como tendo o mesmo significado de "sociedade da informação", é tratado por García Canclini (2009) como uma 
tentativa de universalização arriscada, pois os aspectos cognitivos e socioculturais estão distribuídos e são apropriados de modos muito diversos, gerando diferenças, desigualdades e desconexões.

Outras designações, como "sociedade do consumo" e "globalização", também são generalizadoras e podem incorrer no mesmo erro, ou seja, o de incluir em seu discurso movimentos heterogêneos e grupos sociais excluídos que não fazem parte dessas supostas sociedades. Para García Canclini, pelo fato de as inovações tecnológicas e os saberes científicos estarem desigualmente distribuídos entre países ricos e pobres, de acordo com os níveis educacionais e as faixas etárias, “[...] a problemática da diversidade cultural e os estudos sobre ela devem fazer parte da consideração teórica, da investigação empírica e do planejamento de políticas neste campo" (GARCÍA CANCLINI, 2009, p. 226).

Nesse sentido, seria necessário para o desenvolvimento de uma "sociedade do conhecimento" políticas públicas internacionais que garantam a participação do maior número possível de línguas e culturas, que protejam a propriedade intelectual bem como o controle dos oligopolistas culturais, além de se opor às comercializações lucrativas dos gostos internacionais de massa. No entanto, García Canclini (2009) questiona sobre como construir uma "sociedade do conhecimento" se produções de culturas milenares não são reproduzidas nas telas do mundo e suas músicas não constam nas prateleiras das lojas musicais.

[...] vigorosas culturas históricas, com centenas de milhares de falantes, são excluídas dos mercados musicais ou colocadas nestas prateleiras marginais das lojas de discos que, paradoxalmente, recebem o título de world music? Não há condições de efetiva mundialização se as formas de conhecimento e representação expressas nos filmes árabes, hindus, chineses e latino-americanos estão quase ausentes das telas dos demais continentes. Não circulam nas áreas culturais e linguísticas próximas nem nas cidades do Primeiro Mundo (Los Angeles, Nova York, Berlim), habitadas por milhões de migrantes dessas regiões que seriam públicos "naturais". (GARCÍA CANCLINI, 2009, p. 237).

Dessa forma, o caráter incipiente de uma dita "sociedade do conhecimento" fica evidente quando o mercado mundial despreza a manifestação cultural de parcelas significativas de sociedades milenares em detrimento de fazer circular os enlatados hegemônicos do tal primeiro mundo. Essa aberração 
acontece não só na produção cultural, mas na imposição hegemônica da língua inglesa, na ciência e na tecnologia. Essa é uma das características antidemocráticas do processo de "globalização" que retira dos cidadãos o poder de decisão sobre os rumos dos novos processos de interdependência entre capitais, investimentos, produção, circulação e consumo de bens. Para García Canclini (2009, p. 206), “[...] decisões e as vantagens concentram-se em algumas poucas elites financeiras, industriais e políticas transnacionais, residentes dos Estados Unidos, Europa e Japão”.

A partir deste cenário de hegemonia das elites financeiras sobre a produção, circulação e uso dos bens culturais, passamos a refletir sobre o que é "globalização", a quem serve e qual o seu papel no mundo. García Canclini (2007) relata que é curioso dar o nome de "globalização" à "luta de todos contra todos":

Curioso é que essa disputa de todos contra todos, em que fábricas vão falindo, empregos são destruídos e explodem a migração em massa e os conflitos étnicos e regionais, receba o nome de globalização. Chama a atenção o fato de empresários e políticos interpretarem a globalização como a convergência da humanidade rumo a um futuro solidário, e que até muitos críticos do processo entendam essa devastação como o processo por meio do qual todos acabaremos homogeneizados. (GARCÍA CANCLINI, 2007, p. 8).

Essa disputa de todos contra todos, que destrói empregos e coloca milhares de famílias nas rotas de migração, serve ao capital e tem papel bem claro no imaginário do mundo, ou seja, passar a ideia de integração e solidariedade entre os povos, escondendo ou minimizando as atrocidades cometidas pelo funcionamento do capital no mundo. Além disso, esse modo de pensar acaba por, de alguma maneira, blindar o funcionamento do mundo capitalista e a dita "globalização" como única forma de promover a universalização dos benefícios para o mundo. Para o autor, esse modo de pensar faz com que as pessoas concluam que "[...] o capitalismo é o único modelo possível para interação entre os homens e a globalização sua etapa superior e inevitável" (GARCÍA CANCLINI, 2007, p. 8). Discurso esse que cria um modelo em que ninguém consegue viver alheio a ele, ou seja, nem os pobres podem romper com o global, 
tendo em vista que as empresas que os empregam, nos mais variados países e na maioria das vezes, não pertencem ao local em que se encontram.

Nessa perspectiva, a "globalização imaginada", assim como a ideia de "sociedade da informação", é uma estratégia para colocar em prática a hegemonia dos conglomerados industriais, das corporações financeiras, das grandes empresas que atuam na indústria cultural por meio da música, do cinema, da televisão e da informática, que se apropriam de recursos naturais, culturais e do trabalho dos países pobres. Para García Canclini (2007) o que se costuma chamar de "globalização" apresenta-se como um conjunto de processos de "homogeneização e de fragmentação do mundo" (GARCÍA CANCLINI, 2007, p. 33) que reordenam as diferenças e as desigualdades sem suprimi-las.

\section{Considerações finais}

O artigo abordou a problemática vinculada ao fato de que a Ciência da Informação, ao utilizar a expressão "sociedade da informação" de forma passiva, acaba por assumir uma postura acrítica diante da ciência e, consequentemente, pode negligenciar olhares epistemológicos ao campo, principalmente vinculados aos excluídos dessa suposta sociedade.

Por meio das ideias de Mattelart, Bauman e García Canclini, foi possível perceber que os autores convergem em relação à lógica do capital quando o assunto se refere a encontrar um responsável pela expansão da tragédia global que vem promovendo prioritariamente prejuízos à humanidade, tanto no aspecto de integração dos povos quanto no que se refere ao respeito às culturas e às diversidades, além da precarização das relações de trabalho e o crescimento do processo migratório no mundo.

Ainda que eles apontem alguns aspectos positivos promovidos principalmente pelas novas tecnologias, como maior contato entre pessoas e flexibilidade de acesso à informação, os escritores demonstram que o responsável por essa tragédia de relacionamento e segregação entre os povos é o capitalismo neoliberal e sua expansão sem precedentes. 
Outros autores partilham desse pensamento. Newton Duarte, por exemplo, relata que a tal "sociedade do conhecimento" é uma ideologia produzida pelo capitalismo: "A assim chamada sociedade do conhecimento é uma ideologia produzida pelo capitalismo, é um fenômeno no campo da reprodução ideológica do capitalismo" (DUARTE, 2003, p. 13). Pedro Demo (2000) relata que nada mudou em relação ao processo de "globalização", que foi responsável por reforçar ainda mais o domínio estadunidense e o funcionamento da mais-valia. Segundo o autor, os estadunidenses, por meio da ideia de "globalização", transformaram o mundo em uma "pequena aldeia", o que ele chama de "dolarização do mundo" (DEMO, 2000, p. 28) refazendo a trajetória colonizadora com maior vigor e discriminação. Para ele, a dita "sociedade da informação" informa bem menos do que se imagina e a "globalização" engloba bem menos pessoas e povos do que se pretende.

Dessa forma, esse texto pontuou apenas alguns autores - dentre a gama infindável de pensadores que trabalham com a temática - que seguem o mesmo caminho de Mattelart, Bauman e García Canclini quando a questão é apontar o responsável pela tragédia da "sociedade global". De modo geral, a pluralidade de termos e expressões, como "globalização", "sociedade global", "sociedade da informação", "sociedade do conhecimento", "era da informação", "era do conhecimento", entre outros, nada mais é do que a dança livre do capital em busca de potencializar a mais valia.

\section{Referências}

ARAÚJO, Carlos Alberto Ávila. Teoria crítica da informação no Brasil: a contribuição de Armand Mattelart. RECIIS: Revista Eletrônica de Comunicação, Informação \& Inovação em Saúde, Rio de Janeiro, v. 3, n. 3, p. 112-119, set. 2009.

BAUMAN, Zygmunt. Globalização: as consequências humanas. Rio de Janeiro: Zahar, 1999.

BAUMAN, Zygmunt. Medo líquido. Rio de Janeiro: Zahar, 2008.

BAUMAN, Zygmunt. Modernidade líquida. Rio de Janeiro: Zahar, 2001. 
DEMO, Pedro. Ambivalências da sociedade da informação. Ciência da Informação, Brasília, v. 29, n. 2, p. 37-42, maio/ago. 2000.

DUARTE, Newton. Sociedade do conhecimento ou sociedade das ilusões?

Campinas: Autores Associados, 2003.

DUFF, Alistair S. The "Information Society" as paradigma: a bibliometric inquiry. Journal of Information Science, [s. l.], v. 21, n. 5, p. 390-395, 1995.

FREITAS, Lídia Silva de. A memória polêmica da noção de sociedade da informação e sua relação com a área de informação. Informação \& Sociedade, Paraíba, v. 12, n. 2, p. 1-23, 2002.

GARCÍA CANCLINI, Néstor. A globalização imaginada. São Paulo: Iluminuras, 2007.

GARCÍA CANCLINI, Néstor. Diferentes, desiguais e desconectados: mapas da interculturalidade. Rio de Janeiro: UFRJ, 2009.

HAYASHI, Yujiro. The information society: from hard to soft. Tokyo: Kodansha Gendai Shinso, 1969.

MACHLUP, Fritz. The production and distribution of knowledge in the United States. Princeton, NJ: Princeton University Press, 1962.

MASUDA, Yoneji. Introdução à sociedade da informação. Tokyo: PerikanSha, 1968.

MATTELART, Armand. História da sociedade da informação. São Paulo: Edições Loyola, 2006.

MATTELART, Armand; MATTELART, Michéle. História das teorias da comunicação. 3. ed. São Paulo: Edições Loyola, 2000.

NUNES, Jefferson Veras; ALMEIDA JÚNIOR, Oswaldo Francisco de. Revisitando o conceito de sociedade da informação: o social e o técnico em interação? In: CAVALCANTE, Lidia; PINTO, Virginia Bentes; VIDOTTI, Silvana Aparecida Borsetti Gregorio (org.). Ciência da Informação e contemporaneidade: tessituras e olhares. Fortaleza: EdUFC, 2013. v. 1, p. 3158 .

PARKER, Edwin B. Information and society: a report to the National Commission on Libraries and Information Science. Washington, D.C.: National Commission on Libraries and Information Science, 1973. Disponível em: https://hdl.handle.net/2027/mdp.39015024838792. Acesso em: 15 fev. 2020. 


\title{
The illusion of an information society in Information Science: the term from the critical perspective of Mattelart, Bauman and García Canclini
}

\begin{abstract}
This study reflects on the term "information society" widely used in articles in the area of Information Science, trying to comprehend whether the term is used in a "passive" or "critical" way and what impacts this notion brings to the field. To this, the aim was to analyze the use of the term "information society" in the area at the national and international levels. This is a literature review carried out using two databases: the "Library and Information Science Abstracts", which remains a reference in the international summary and indexing service for library professionals and other information specialists, and the "Base de Dados de Referência de Artigos de Periódicos em Ciência da Informação", which has become a reference in research in the area of Information Science in Brazil. The results showed that more than $80 \%$ of researchers, both national and international, use the term passively in their texts. Based on these data, the article draws on the ideas of Mattelart, Bauman and García Canclini and concludes by reflecting on the risks of the area accepting the notion of "information society" uncritically and points out, through the authors, that this term was created for mitigate the atrocities promoted by the expansion of economic interests on a global scale, expanding the performance of free capital that made the world of labor mobile and replaceable, in addition to imposing the valorization of cultural and scientific production in high income countries.
\end{abstract}

Keywords: Information Society. Knowledge Society. Globalization. Global Society. Information Science.

Recebido: $17 / 04 / 2020$

Aceito: 28/08/2020

\section{Declaração de autoria}

Concepção e elaboração do estudo: Ciro Athayde Barros Monteiro

Coleta de dados: Ciro Athayde Barros Monteiro

Análise e discussão de dados: Ciro Athayde Barros Monteiro; Oswaldo Francisco de Almeida Junior

Redação e revisão do manuscrito: Ciro Athayde Barros Monteiro; Oswaldo Francisco de Almeida Junior

\section{Como citar}

MONTEIRO, Ciro Athayde Barros; ALMEIDA JÚNIOR, Oswaldo Francisco de. A ilusão de uma sociedade da informação na Ciência da Informação: o termo sob a perspectiva crítica de Mattelart, Bauman e García Canclini. Em Questão, Porto Alegre, v. 27, n. 2, p. 294-322, abr./jun. 2021.

Doi: http://dx.doi.org/10.19132/1808-5245272.294-322 